\title{
Associations of lean and fat mass measures with whole body bone mineral content and bone mineral density in female adolescent weightlifters and swimmers
}

\author{
Şükran Nazan Koşar \\ Hacettepe University, Faculty of Sport Sciences, Nutrition and Metabolism in Exercise, Beytepe, Ankara, Turkey. \\ E-mail:nazank@hacettepe.edu.tr,nazankosar@gmail.com \\ Received: 22 February 2016, Revised: 5 April 2016, Accepted: 13 April 2016
}

SUMMARY: Koşar ŞN. Associations of lean and fat mass measures with whole body bone mineral content and bone mineral density in female adolescent weightlifters and swimmers. Turk J Pediatr 2016; 58: 79-85.

Body composition and sport participation have been associated with bone mass. The purpose of this study was to determine the associations of lean and fat mass measures with whole body bone mineral content (BMC) and bone mineral density (BMD) in female adolescent weightlifters, swimmers and non-athletic counterparts. This study included a total of 25 female adolescents (mean age: $15.3 \pm 1.1$ years). Body composition and bone mass were measured by dual-energy X-ray absorptiometry. In most of the studied variables weight lifters had higher values compared to swimmers and non-athletes $(p<0.05)$. No significant difference was observed between swimmers and non-athletes $(p>0.05)$. Lean and fat mass measures were positively associated with BMC and BMD for the total participants $(\mathrm{p}<0.05)$ while the associations differed when the study groups were analysed separately. In conclusion, both lean and fat mass measures were strongly related to BMC and BMD in female adolescents while these associations differed in swimmers, weightlifters and non-athletes.

Key words: lean body mass, fat mass, bone mass, weightlifters, swimmers, adolescent athlete.

Childhood and adolescence periods are important for bone mineral acquisition which increases in both girls and boys with age throughout these periods. Bone mineralization is affected by several factors including gender, ethnicity, heredity, body composition, diet, physical activity and hormones. Among these factors physical activity and diet are the modifiable lifestyle factors influencing both bone mass and body composition.

Long term physical activity and sport participation improve bone health particularly during the second decade of life when bone development accelerates and bone mineral density peaks ${ }^{1-6}$. Indeed, exercise participation during childhood results in $0.6 \%$ to $1.7 \%$ greater increase per year in bone accrual ${ }^{5}$.

Moreover, recently the link between body composition components [lean mass (LM), fat mass (FM)] and bone mass [i.e., bone mineral content (BMC) and bone mineral density (BMD)] have gained great interest in athletic and non-athletic populations. Studies showed that increased LM is the best predictor of bone mass in adults, youth, athletes, non-athletes and patients with chronic diseases ${ }^{1,7-18}$ Furthermore, some studies claim that excess body fat adversely affects bone mass in adolescents due to increased bone marrow adiposity and increased release of adipokines ${ }^{17,19}$.

Recent advances in dual-energy X-ray absorptiometry (DXA) allow to measure both BMD and body composition simultaneously. DXA measurement of body composition differentiates BMC, FM and LM all together comprising total body mass. Thus, whole body DXA scan with high precision, low scanning time and radiation exposure $(5-10 \mathrm{mSv})$ is a valid and reliable method for body composition and bone health determination in youth ${ }^{20}$. 
Although LM measured by DXA involves tendon, ligaments, facia and aponeuroses in addition to skeletal muscle mass, it is a useful indicator of muscle mass in adults ${ }^{21-22}$ as well as in children and adolescents ${ }^{23}$. It is highly associated with skeletal muscle mass measured by MRI ( $r=0.94$ for the total body and $r=0.91$ for the leg) in elder women ${ }^{24}$. Furthermore, as the skeletal muscle mass is the dominant tissue in arms and legs, recently it has been suggested to use DXA-derived appendicular LM as a measure of skeletal muscularity. In this respect, it has been shown that total body BMC was highly correlated with total body lean mass index (LMI) and appendicular LMI in non-athletic boys and girls ${ }^{25}$. In girls, LM is independently associated with bone mass explaining $67 \%$ of the total variance in whole-body $\mathrm{BMC}^{16}$. A longitudinal study from birth to 6-7 years showed that LM gain in childhood was positively associated with bone size and trabecular volumetric BMD at 6-7 years of age, while no relationships between change in FM and bone were observed ${ }^{14}$. Findings of that study suggests that muscle growth, rather than fat mass gain, may be a more significant factor determining childhood bone development.

Long term sport participation in youth enhances bone mass and LM, and decreases FM. Osteogenic effects of exercise produced by mechanical bone loading as well as exercise induced myokines. However, effects of exercise on bone depends on the type of exercise, intensity and duration of training and these effects are site specific. Research has shown that BMD of young athletes (10-30 years) performing weight bearing, high impact sports (weightlifting, gymnastics, hurdle, judo, karate, volleyball, racket sports and other sports involving jumping) is higher compared to athletes performing non-weight bearing sports and non-athletes ${ }^{26-29}$. On the other hand, BMD of athletes performing non-weight bearing sports (swimming, water polo, cycling etc.) is not higher compared to non-athletic counterparts $6,30-32$. In this regard weightlifting and swimming are the two diverse sports. Weightlifting is a weight bearing, high impact, bone loading activity which improves bone mineralization. While swimming is a nonweight bearing activity producing hypogravity due to buoyancy of the water. Therefore, several studies have shown that swimming

Table I. Comparisons of the Subjects' Characteristics, and the Indices of Bone and Body Composition.

\begin{tabular}{|c|c|c|c|c|c|c|c|c|}
\hline \multirow[b]{2}{*}{ Variable } & \multicolumn{2}{|c|}{$\begin{array}{l}\text { Weightlifters } \\
\qquad(\mathrm{n}=8)\end{array}$} & \multicolumn{2}{|c|}{$\begin{array}{l}\text { Swimmers } \\
\quad(n=8)\end{array}$} & \multicolumn{2}{|c|}{$\begin{array}{l}\text { Non-athletes } \\
\quad(n=9)\end{array}$} & \multirow[b]{2}{*}{$\mathrm{F}$} & \multirow[b]{2}{*}{$\mathrm{p}$} \\
\hline & Mean & SD & Mean & SD & Mean & SD & & \\
\hline Age (years) & 15.4 & 1.2 & 15.3 & 1.2 & 15.3 & 1.0 & 0.023 & .977 \\
\hline Height $(\mathrm{cm})$ & 158.0 & 5.3 & 162.2 & 3.8 & 160.8 & 5.7 & 1.418 & .263 \\
\hline Weight (kg) & $67.3^{c}$ & 16.4 & 54.8 & 7.2 & 51.9 & 4.4 & 5.073 & .015 \\
\hline BMI $\left(\mathrm{kg} / \mathrm{m}^{2}\right)$ & $26.8^{\mathrm{a}}$ & 6.0 & 20.8 & 2.5 & 20.1 & 1.6 & 7.920 & .003 \\
\hline DXA body mass $(\mathrm{kg})$ & $67.9^{c}$ & 16.1 & 55.5 & 7.1 & 52.7 & 4.3 & 5.135 & .015 \\
\hline FM (kg) & $22.8^{\mathrm{b}}$ & 9.3 & 14.2 & 2.8 & 15.6 & 3.7 & 4.939 & .017 \\
\hline FM percentage (\%) & $32.5^{\mathrm{b}}$ & 5.4 & 25.4 & 2.8 & 29.4 & 5.1 & 4.744 & .019 \\
\hline FMI $\left(\mathrm{kg} / \mathrm{m}^{2}\right)$ & $9.1^{\mathrm{a}}$ & 3.5 & 5.4 & 1.1 & 6.0 & 1.4 & 5.984 & .008 \\
\hline LM (kg) & $42.8^{c}$ & 6.7 & 39.3 & 4.9 & 35.0 & 2.3 & 5.417 & .012 \\
\hline LMI $\left(\mathrm{kg} / \mathrm{m}^{2}\right)$ & $17.1^{\mathrm{a}}$ & 2.3 & 14.9 & 1.5 & 13.5 & 0.5 & 10.516 & .001 \\
\hline Appendicular LM (kg) & $19.6^{\mathrm{c}}$ & 3.9 & 16.7 & 2.2 & 15.2 & 1.3 & 6.084 & .008 \\
\hline Appendicular LMI $\left(\mathrm{kg} / \mathrm{m}^{2}\right)$ & $7.8^{\mathrm{a}}$ & 1.4 & 6.3 & 0.7 & 5.9 & 0.3 & 11.021 & .000 \\
\hline Total body BMC (g) & 2.3 & 0.4 & 2.1 & 0.3 & 2.1 & 0.2 & 1.971 & .163 \\
\hline Total body BMD $\left(\mathrm{g} / \mathrm{cm}^{2}\right)$ & $1.3^{\mathrm{a}}$ & 0.1 & 1.1 & 0.1 & 1.1 & 0.1 & 5.762 & .010 \\
\hline Total body BMD z score & $2.1^{\mathrm{a}}$ & 1.1 & 0.4 & 0.9 & 0.8 & 1.0 & 6.544 & .006 \\
\hline
\end{tabular}

BMI: body mass index, FM: fat mass, FMI: fat mass index, LM: lean mass, LMI: lean mass index, BMC: bone mineral content, BMD: bone mineral content; ${ }^{a}$ Weightlifters significantly different from both swimmers and non-athletes, bWeightlifters significantly different from swimmers, cWeightlifters significantly different from non-athletes, $\mathrm{p}<0.05$. 
is not beneficial for bone health ${ }^{33-34}$. Indeed, bone measurements of swimmers were lower by $4-19 \%$ compared to the athletes in any other sport ${ }^{30}$. In addition to benefit from the buoyancy of water, body fat percentage of the swimmers is higher compared to the athletes competing in other sport branches.

Studies examining the associations of LM and FM measures with BMC and BMD in youth reported findings on non-athletic populations ${ }^{25}$. There is no study reporting these associations in adolescent female athletes, particularly for the two distinguished sports weightlifters and swimmers. Thus the purpose of this study was to determine the associations of lean and fat mass measures with whole body bone mineral content (BMC) and bone mineral density (BMD) in female adolescent weightlifters, swimmers and non-athletic counterparts.

\section{Material and Methods}

\section{Study design}

Methods and procedures of the study were approved by the Human Subjects Institutional Review Board at Hacettepe University (decree no: GO 14/634-06). The study was carried out at the Laboratory of Nutrition and Metabolism in Exercise at Faculty of Sport Science, Hacettepe University. Participants were instructed not to participate in heavy exercise and not to take too much caffeine containing drinks the day before the measurement.

\section{Participants}

Participants of this study were comprised of weight lifters $(n=8)$ and swimmers $(n=8)$ with at least 1 year of training experience and non-athletic age-matched counterparts $(n=9)$ with no training history for the past year. Participant's mean age was $15.3 \pm 1.1$ years (range, 14.1-16.6 years). Mean training experiences for weightlifters and swimmers were $2.6 \pm 1.6$ and $6.5 \pm 2.6$ years, respectively. The number of training sessions per week was at least 6. Mean training hours per week were $19.6 \pm 2.3$ for weightlifters and $15.7 \pm 4.5$ for swimmers. All participants except two swimmers were eumenorrheic with a menarche age of 13 years. Two swimmers have not got their first period yet. Procedures of the study were explained to the participants. Their written informed consent as well their parents' were obtained. Participants who had any chronic disease or used nutritional supplements during the last 3 months were excluded from the study.

\section{Procedures}

\section{Anthropometric measurements}

Height was measured by a wall stadiometer (Holtain stadiometer, UK) to the nearest 0.1 $\mathrm{cm}$ and body weight was measured by a scale (Tanita TBF-401A, Germany) to the nearest 0.1 $\mathrm{kg}$. BMI was calculated as weight in kilograms divided by the square of height in meters.

\section{Assessment of body composition and bone mineral density}

The whole body composition and bone mineral density were measured by a narrow fan bean $\left(4.5^{\circ}\right)$ DXA scanner (Lunar Prodigy Pro; GE Healthcare, Madison, WI, USA) using a total body scan mode. The data was analysed with GE Encore v14.1 software. DXA calibration was completed using phantoms as per manufacturer's standard directions in the morning before measurements. The scanning mode was automatically selected by the DXA device according to body size.

Body composition variables chosen for the present study included three measures of total adiposity, namely the percentage of body fat $(\% \mathrm{BF})$, fat mass (FM), fat mass index (FMI) and three measures of lean mass, namely, the lean mass (LM), lean mass index (LMI) and appendicular LMI. Height-adjusted indexes were calculated as follows: BMI [weight $(\mathrm{kg}) /$ height $^{2}$ $(\mathrm{m})]$, FMI [FM (kg)/height $\left.{ }^{2}(\mathrm{~m})\right]$, LMI [LM $(\mathrm{kg}) /$ height $\left.^{2}(\mathrm{~m})\right]$, and appendicular LMI [LM (arms and legs) $(\mathrm{kg}) /$ height $\left.^{2}(\mathrm{~m})\right]$. Bone mass measures included in this study were whole body BMC (g) and BMD $\left(\mathrm{g} \cdot \mathrm{cm}^{2}\right)$.

\section{Statistical analysis}

Descriptive statistics were calculated as means and standard deviations. Analysis of co-variance was used to compare means of bone indices by group with the BMI as covariate. Partial correlation analysis was performed to determine the associations between LMI and BMC/BMD by adjusting for FMI/FM as a covariate in order to eliminate the FM/FMI factor. SPSS 22 was used for the analysis and significance level was set as $\mathrm{p}<0.05$. 


\section{Results}

One way ANOVA results revealed that weightlifters, swimmers and non-athletes were similar with respect to age and height $(\mathrm{p}>0.05$, Table I). Weightlifters had significantly higher values compared to both swimmers and nonathletes in BMI, FMI, LMI and appendicular LMI, ( $<<0.05$, Table I). In addition, weightlifters had higher FM and FM percentages than swimmers $(p<0.05$, Table I). Body weight, DXA measured body mass, LM and appendicular LM were higher than non-athletes $(p<0.05)$ but were similar to swimmers ( $p>0.05$, Table I). Swimmers and non-athletes were similar in all variables measured ( $p>0.05$, Table I).

Weightlifters had significantly higher values compared to both swimmers and non-athletes in total body BMD and $z$ scores for total body BMD ( $<<0.05$, Table I). Differences in total body BMD disappeared when the groups were compared by analysis of covariance with the BMI as co-variate $\left(\mathrm{F}_{(2,22)}=1.121, \mathrm{p}=0.345\right)$. Similarly, no difference was observed among the groups in total body BMC $\left(\mathrm{F}_{(2,22)}=0.061\right.$, $\mathrm{p}=0.941)$.

Pearson correlation coefficients between bone and body composition indices for each group and total participants were presented in Table II. Results for total participants showed that all bone indices were significantly correlated with all LM and FM measures $(p<0.05$, Table
II). While the results for each group showed that these associations were changing with respect to study group with stronger relations observed for weightlifters than swimmers, while the associations disappeared in non-athletes (Table II). In addition, findings showed that the associations between bone indices and LM measures were stronger than FM measures. The associations of bone mass indices with appendicular LM and appendicular LMI were stronger than total LM and total LMI (Table II). No significant association was observed between total body LMI, appendicular LMI, and bone indices ( $p>0.05)$ when FM and FMI were used as covariates (Table III). In this respect non-significant small to moderate associations were observed for the total study participants and swimmers (Table III) where the associations for appendicular LMI were higher than the associations for total body LMI.

\section{Discussion}

This is the first study comparing body composition and bone mass of female adolescent weightlifters and swimmers. Moreover, the study is unique as it reports the associations of lean and fat mass measures with whole body bone mineral content and bone mineral density in female adolescent athletes performing weight-bearing and non-weight bearing sports. Main findings of this study revealed that in most of the variables weight lifters had higher

Table III. Partial Correlation Coefficients Adjusting for FMI/FM Between LMI and BMC/BMD Among Participants.

\begin{tabular}{|c|c|c|c|c|}
\hline & \multicolumn{2}{|c|}{ Adjusting for FMI } & \multicolumn{2}{|c|}{ Adjusting for FM } \\
\hline & $\begin{array}{c}\text { Total body } \\
\text { LMI }\left(\mathrm{kg} / \mathrm{m}^{2}\right)\end{array}$ & $\begin{array}{l}\text { Appendicular } \\
\text { LMI }\left(\mathrm{kg} / \mathrm{m}^{2}\right)\end{array}$ & $\begin{array}{l}\text { Total body LMI (kg/ } \\
\left.\mathrm{m}^{2}\right)\end{array}$ & $\begin{array}{l}\text { Appendicular } \\
\text { LMI }\left(\mathrm{kg} / \mathrm{m}^{2}\right)\end{array}$ \\
\hline \multicolumn{5}{|l|}{ BMC (g) } \\
\hline Weightlifters $(n=8)$ & -0.077 & 0.086 & -0.252 & -0.159 \\
\hline Swimmers $(\mathrm{n}=8)$ & 0.658 & 0.705 & 0.506 & 0.600 \\
\hline Non-athletes $(n=9)$ & -0.317 & 0.070 & -0.322 & 0.053 \\
\hline Total $(n=25)$ & 0.333 & 0.464 & 0.238 & 0.339 \\
\hline \multicolumn{5}{|l|}{$\operatorname{BMD}\left(\mathrm{g} / \mathrm{cm}^{2}\right)$} \\
\hline Weightlifters $(n=8)$ & -0.078 & 0.248 & -0.046 & 0.238 \\
\hline Swimmers $(\mathrm{n}=8)$ & 0.647 & 0.697 & 0.501 & 0.596 \\
\hline Non-athletes $(n=9)$ & -0.051 & 0.255 & -0.116 & 0.224 \\
\hline Total $(n=25)$ & 0.387 & 0.555 & 0.366 & 0.519 \\
\hline
\end{tabular}

LM: lean mass, LMI: lean mass index, FM: fat mass, FMI: fat mass index, BMC: bone mineral content, BMD: bone mineral content; ${ }^{*} \mathrm{p}<0.05,{ }^{* *} \mathrm{p}<0.01$ 
values compared to swimmers and non-athletes, while the swimmers and non-athletes were similar. Moreover, lean and fat mass measures were positively associated with BMC and BMD for the total participants $(\mathrm{p}<0.05)$ while the associations differed when the study groups were analysed separately indicating that these associations might be specific to population i.e., athletes vs. non-athletes and the type of sport (weight bearing vs. non-weight bearing).

The present study showed that female adolescent weightlifters had higher BMI, FMI, LMI, appendicular LMI compared to agematched swimmers and non-athletes indicating that they were heavier with respect to their height and that they possessed more fat, lean mass and appendicular lean mass in proportion to their height compared to swimmers and non-athletes. Since weightlifters compete at certain weight categories they need to maintain their body weight within the specified ranges.

Compared to swimmers, weightlifters had higher FM and FM percentages $(p<0.05$, Table I) indicating that in the present study weightlifters are not well conditioned to develop lean mass. On the other hand, swimmers' training experience were higher than weightlifters as starting age for swimmers is earlier than for weightlifters due to the possible adverse effects of weightlifting on skeletal growth and development.

In the present study, weightlifters had higher values of total body $\mathrm{BMD}$ and total $\mathrm{BMC}$ than swimmers and non-athletes while the differences were significant for only total body BMD. However, this difference disappeared when the groups were compared by using BMI as covariate. Small sample size of the study could be the reason for non-significant differences. As for the $z$ scores for total BMD, female adolescent weightlifters had significantly higher values compared to swimmers and non-athletes.

Although swimmers had higher LM and lower FM indices than non-athletes the differences were not significant (Table I). In terms of total body BMD and BMC swimmers and nonathletes were almost identical indicating that swim training did not affect bone measures. This finding confirms other existing studies on the topic ${ }^{6,31,32}$. When $z$ scores for total body BMD were compared, swimmers tend to have two times lower values than non-athletes although the differences were not significant. Compared to non-athletes lower $z$ scores in adolescent swimmers might be due to the adverse effects of long term weight reducing effect of swim training on the skeleton. In order to overcome this effect, exercise training for lean mass development and high impact loading activities should be emphasized in this particular group ${ }^{26-29}$.

This study showed moderate to strong positive associations between bone measures, and LM and FM measures when the data for the total participants was analyzed $(\mathrm{p}<0.05$, Table II). However, when the same analysis was performed for the study groups separately, we observed that the strength and the direction of the associations were specific to the group. The relations of bone indices with the LM and FM indices were stronger in weightlifters compared to swimmers and non-athletes. In non-athletes, only BMC was significantly associated with LM and appendicular LM (Table II).

Similarly the associations between bone indices and LM measures were stronger than FM measures for the total participants and swimmers while in weightlifters the associations of FM measures with bone measures were stronger than LM measures. Others scientists reported similar findings: compared to FM measures, LM indices associated with bone indices in Chinese children and adolescents ${ }^{25}$. In line with the literature ${ }^{25}$ we found that appendicular LM and appendicular LMI were the stronger predictors of bone measures than total LM and total LMI (Table II) indicating its significance as a criterion to follow up musculoskeletal development in youth. In line with the present findings, several other studies $1,7,8,11,14-18$ demonstrated that LM and LMI are the strongest predictors of bone mass in diverse populations. In this respect, a $1-\mathrm{kg}$ increase in LM was associated with $28.42 \mathrm{~g}$ and $0.007 \mathrm{~g} / \mathrm{cm}^{2}$ increase in whole-body BMC and $\mathrm{BMD}$, respectively ${ }^{11}$. On the other hand a $1-\mathrm{kg}$ increase in fat mass was associated with $9.32 \mathrm{~g}$, and $0.002 \mathrm{~g} / \mathrm{cm}^{2}$ increase in whole body BMC and BMD, respectively ${ }^{11}$.

Reference values for DXA measured body composition measures were reported for children and adolescents from various countries $25,35,36$ and for the athletes with various age groups ${ }^{4}$. 
As total and appendicular LM and LMI are becoming an important criterion for observing musculoskeletal deficits in health and disease there is a need to develop gender and age specific reference values in youth and adult athletic and non-athletic populations in Turkey.

Non-significant small to moderate associations of BMC and BMD with the LM measures were observed for the total study participants and swimmers when FM and FMI were used as covariates (Table III) where the correlation coefficients for appendicular LMI were higher than those for total body LMI. This finding also suggests population specific relations of the studied parameters. Non-significant relations in swimmers might be due to the small sample size of the study.

Main limitation of the present study is its small sample size, therefore, the findings of the study cannot be generalized. Similar studies with larger sample sizes are worth conducting to elucidate the differences in bone measures among various sport disciplines. Additionally, this study is cross-sectional in nature and longitudinal studies need to be carried out to explore the long term musculoskeletal development and the relations of bone and body composition measures in response to sport participation.

In conclusion, both lean and fat mass measures were strongly related to BMC and BMD in female adolescents while these associations differed in weightlifters, swimmers and nonathletes. LM indices, particularly appendicular LM and appendicular LMI were found to be strong predictors of BMC and BMD.

\section{Acknowledgements}

I like to thank the participants and their parents for their cooperation in this project, and my colleagues who assisted in data collection.

\section{REFERENCES}

1. Calbet JA, Dorado C, Díaz-Herrera P, RodríguezRodríguez LP. High femoral bone mineral content and density in male football (soccer) players. Med Sci Sports Exerc 2001; 33: 1682-1687.

2. Fehling PC, Alekel L, Clasey J, Rector A, Stillman RJ. A comparison of bone mineral densities among female athletes in impact loading and active loading sports. Bone 1995; 17: 205-210.

3. Nichols JF, Rauh MJ, Barrack MT, Barkai HS. Bone mineral density in female high school athletes: interactions of menstrual function and type of mechanical loading. Bone 2007; 41: 371-377.

4. Santos DA, Dawson JA, Matias CN, et al. Reference values for body composition and anthropometric measurements in athletes. PLoS One 2014; 9: e97846.

5. Specker B, Thiex NW, Sudhagoni RG. Does exercise influence pediatric bone? A systematic review. Clin Orthop Relat Res 2015; 473: 3658-3672.

6. Tenforde AS, Fredericson M. Influence of sports participation on bone health in the young athlete: a review of the literature. PM R 2011; 3: 861-867.

7. Crabtree NJ, Kibirige MS, Fordham JN, et al. The relationship between lean body mass and bone mineral content in paediatric health and disease. Bone 2004; 35: 965-972.

8. El Hage R, Moussa E, Jacob C. Bone mineral content and density in obese, overweight, and normal-weighted sedentary adolescent girls. J Adolesc Health 2010; 47: 591-595.

9. Ho-Pham LT, Nguyen UD, Nguyen TV. Association between lean mass, fat mass, and bone mineral density: a meta-analysis. J Clin Endocrinol Metab 2014; 99: 30-38.

10. Jeddi M, Dabbaghmanesh MH, Ranjbar Omrani G, Ayatollahi SM, Bagheri Z, Bakhshayeshkaram M. Relative importance of lean and fat mass on bone mineral density in Iranian children and adolescents. Int J Endocrinol Metab 2015; 13: e25542.

11. Kâ K, Rousseau MC, Lambert M, et al. Association between lean and fat mass and indicators of bone health in prepubertal caucasian children. Horm Res Paediatr 2013; 80: 154-162.

12. Maisnam I, Dutta D, Mukhopadhyay S, Chowdhury S. Lean mass is the strongest predictor of bone mineral content in type-2 diabetes and normal individuals: an eastern India perspective. J Diabetes Metab Disord 2014; 13:90.

13. Marwaha RK, Garg MK, Bhadra K, Tandon K. Bone mineral content has stronger association with lean mass than fat mass among Indian urban adolescents. Indian J Endocrinol Metab 2015; 19: 608-615.

14. Moon RJ, Cole ZA, Crozier SR, et al. Longitudinal changes in lean mass predict pQCT measures of tibial geometry and mineralisation at 6-7 years. Bone 2015; 75: $105-110$.

15. Torres-Costoso A, Gracia-Marco L, Sánchez-López M, et al. Lean mass as a total mediator of the influence of muscular fitness on bone health in schoolchildren: a mediation analysis. J Sports Sci 2015; 33: 817-830.

16. Vicente-Rodriguez G, Ara I, Perez-Gomez J, Dorado C, Calbet JA. Muscular development and physical activity as major determinants of femoral bone mass acquisition during growth. Br J Sports Med 2005; 39: 611-616.

17. Wey HE, Binkley TL, Beare TM, Wey CL, Specker BL. Cross-sectional versus longitudinal associations of lean and fat mass with pQCT bone outcomes in children. J Clin Endocrinol Metab 2011; 96: 106-114.

18. Witzke KA, Snow CM. Lean body mass and leg power best predict bone mineral density in adolescent girls. 
Med Sci Sports Exerc 1999; 31: 1558-1563.

19. Mosca LN, Goldberg TB, da Silva VN, et al. Excess body fat negatively affects bone mass in adolescents. Nutrition 2014; 30: 847-852.

20. Helba M, Binkovitz LA. Pediatric body composition analysis with dual-energy X-ray absorptiometry. Pediatr Radiol 2009; 39: 647-656.

21. Kim J, Wang Z, Heymsfield SB, Baumgartner RN, Gallagher D. Total-body skeletal muscle mass: estimation by a new dual-energy X-ray absorptiometry method. Am J Clin Nutr 2002; 76: 378-383.

22. Webber CE, Barr RD. Age- and gender-dependent values of skeletal muscle mass in healthy children and adolescents. J Cachexia Sarcopenia Muscle 2012; 3: $25-29$.

23. Kim J, Shen W, Gallagher D, et al. Total-body skeletal muscle mass: estimation by dual-energy X-ray absorptiometry in children and adolescents. Am J Clin Nutr 2006; 84: 1014-1020.

24. Chen Z, Wang Z, Lohman T, et al. Dual-energy X-ray absorptiometry is a valid tool for assessing skeletal muscle mass in older women. J Nutr 2007; 137: 27752780 .

25. Guo B, Wu Q, Gong J, et al. Relationships between the lean mass index and bone mass and reference values of muscular status in healthy Chinese children and adolescents. J Bone Miner Metab 2015 Nov 19. [Epub ahead of print]

26. Behringer M, Gruetzner S, McCourt M, Mester J. Effects of weight-bearing activities on bone mineral content and density in children and adolescents: a meta-analysis. J Bone Miner Res 2014; 29: 467-478.

27. Ishikawa S, Kim Y, Kang M, Morgan DW. Effects of weight-bearing exercise on bone health in girls: a meta-analysis. Sports Med 2013; 43: 875-892.

28. Laing EM, Wilson AR, Modlesky CM, O’Connor PJ, Hall $\mathrm{DB}$, Lewis RD. Initial years of recreational artistic gymnastics training improves lumbar spine bone mineral accrual in 4- to 8-year-old females. J Bone Miner Res 2005; 20:509-519.

29. Trabelsi H, Elloumi M, Mrad M, et al. Jumping improves lower limbs bone mass and lean mass in elite jumpers. J Sports Med Phys Fitness 2016 Jan 14. [Epub ahead of print]

30. Carbuhn AF, Fernandez TE, Bragg AF, Green JS, Crouse SF. Sport and training influence bone and body composition in women collegiate athletes. J Strength Cond Res 2010; 24: 1710-1717.

31. Gomez-Bruton A, Montero-Marín J, González-Agüero A et al. The Effect of Swimming During Childhood and Adolescence on Bone Mineral Density: A Systematic Review and Meta-Analysis. Sports Med 2016; 46: 365379.

32. Olmedillas H, González-Agüero A, Moreno LA, Casajús JA. Vicente-Rodríguez G. Bone related health status in adolescent cyclists. PLoS One 2011; 6: e24841.

33. Maïmoun L, Coste O, Philibert P, et al. Peripubertal female athletes in high-impact sports show improved bone mass acquisition and bone geometry. Metabolism 2013; 62: 1088-1098.

34. Ferry B, Lespessailles E, Rochcongar P, Duclos M, Courteix D. Bone health during late adolescence: effects of an 8-month training program on bone geometry in female athletes. Joint Bone Spine 2013; 80: 57-63.

35. van der Sluis IM, de Ridder MA, Boot AM, Krenning EP, de Muinck Keizer-Schrama SM. Reference data for bone density and body composition measured with dual energy $x$ ray absorptiometry in white children and young adults. Arch Dis Child 2002; 87: 341-347.

36. Weber DR, Moore RH, Leonard MB, Zemel BS. Fat and lean BMI reference curves in children and adolescents and their utility in identifying excess adiposity compared with BMI and percentage body fat. Am J Clin Nutr 2013; 98: 49-56. 